\title{
Anthropometric model and obesity index of agricultural tractor operators
}

\author{
Joaquim Odilon Pereira ${ }^{1 *}$, José Fernando Schlosser ${ }^{2}$, Darlou de Souza d'Arisbo ${ }^{3}$, Suedêmio \\ de Lima Silva ${ }^{1}$, Miguel Angel Uribe Opazo ${ }^{3}$, Elioneide Jandira de Sales ${ }^{4}$ and \\ Silvanete Severino da Silva ${ }^{5}$
}

\footnotetext{
${ }^{1}$ Department of Environmental and Technological Sciences - Universidade Federal Rural do Semi-Arido - Rua Francisco Mota, 572 cep 59625-900 - Mossoró - RN - Brazil.

${ }^{2}$ Universidade Federal de Santa Maria, Santa Maria - RS - Brazil.

${ }^{3}$ Universidade Estadual do Oeste do Parana - Toledo - Parana - Brazil.

${ }^{4}$ Agricultural and Environmental Engineering, Universidade Federal Rural do Semi-Arido - Rua Francisco Mota, 572 cep 59625-900 Mossoró - RN - Brazil.

${ }^{5}$ Universidade Federal de Campina Grande - Campina Grande - PB - Brazil.
}

Received 26 June, 2014; Accepted 10 October, 2014

\begin{abstract}
This work evaluates the anthropometric model of agricultural tractor operators, presenting a diagnosis of the control instruments' position and the nutritional state of the operators. One hundred and twentyseven agricultural tractors operators were interviewed, of which 23 were selected for the anthropometric evaluation. A rural company, a farm, a farmers' meeting and a tractor dealership were selected for the data collection. Twenty-three anthropometric measurements of each operator were collected and arranged in a table with the dimensions of all operators, presenting statistical results in a $\mathbf{9 0 \%}$ confidence interval. Two types of tractors of medium mass and similar power, representing the largest portion of the market, were used. The positioning of the tractors' controls and their interactions with the operators' area of reach, as well as their accessibility in the command position, were evaluated. The nutritional state of the tractor operators was studied, as well as the relationship of their body mass index with their age. The results show that there was no difference between the general operator types in South Brazil in regard to the measures of their height when standing erect. Seven of the operators who presented BMIs with characteristics of obesity within the normal range were less than $\mathbf{3 8}$ years old, and those with characteristics of pre-obesity and obesity were more than $\mathbf{3 8}$ years old.
\end{abstract}

Key words: Ergonomics, control instruments, command position, body mass index.

\section{INTRODUCTION}

Technological development and the changes evoked by the globalized economy have demanded that rural owners strive for better quality to make agriculture and cattle-raising more competitive, increasing the productivity and reducing the costs. The region of Toledo - PR has a territorial area of 1,198,607 $\mathrm{Km}^{2}$ (urban and

*Corresponding a uthor. E-mail: jodilon@ufersa.edu.br

Author(s) a gree that this artic le remain pemanently open access under the terms of the $\underline{C}$ reative Commons Attribution

License 4.0 Intemational License 
rural area) and is considered to be one of the most productive grain areas of the state. With the progressive mechanization and an increased number of work processes, it is essential that agricultural machinery meets the demands of safety, operator comfort and productivity (Hansson, 1991). In these terms, current machinery must be designed ergonomically when human physicists are looking for a balance between the technical and economic demands. Ergonomy is the science that offers a positive basis for the modern forms of production administration, reducing the incidence of pathologies, especially those that are the consequences of fatigue and of repetitive motion, cumulative trauma and postural injuries (Yadav and Tewari, 1998; lida, 2005).

Nkakine et al. (2008) reported that the amount of physical effort required for control of the machine components may limit performance efficiency and operator comfort. Tewari et al. (2002) stated that if tractor controls are not properly adapted to the operator's anatomy, the performance demanded of him may quickly reach and even exceed the limit of tolerance.

Anthropometry is the Science dealing with dimensions of the human body; it is basically the listing of data and information on human body size. Hansson (1991) reminded that man-machine relationship must be studied using Anthropometric and ergonomic principles, to improve efficiency of machine, reduce risks and enhance operator comfort.

An anthropometric evaluation of agricultural tractor operators requires a referential system for the ergonomic design of their work stations. Although some modern tractors are still financially inaccessible for small- and medium-sized farmers, comfort items have already been added for the operator (electronic control devices, cabins, systems of shock absorption and protection in the event of accidents), incorporated and tied to fluctuations in costs, they still do not address the optimal physiological integration that is the basis of ergonomics.

Few anthropometric studies have been conducted in developing countries. In research that was developed in India (Yadav et al., 1999), the authors concluded that the operators analysed were smaller than the American and European operators in most of the dimensions appraised. In Brazil, studies have been performed to determine the anthropometric measures of agricultural tractor operators, revealing little attention given towards the efficiency, comfort and safety of the operators engaged in the operation of agricultural machines. However, the maximization of agricultural production systems is associated with the modernization of agricultural mechanization. Thus, considering that the anthropometric measures of operators of agricultural machines varies from region to region, and that these measures are ergonomically important in projects of tractors (Schlosser et al., 2000, Victor et al., 2002; Nkakine et al., 2008; Mehta et al., 2008; Kumar et al., 2009) with anthropometry.
A study by Schlosser et al. (2000) reports that the correct disposition and dimensions of the components of the operator's work station, such as the steering wheel, seat and means of entrance and exit, is important for the process of adapting the machine to the operator. In principle, they do not greatly increase production costs and help to improve the operator's comfort.

The dimensions of the steps for accessing agricultural tractors should be from 0.20 to $0.30 \mathrm{~m}$, with equal heights, landings of $0.10 \mathrm{~m}$, distance of the tractor of 0.15 $\mathrm{m}$ and an inclination from 65 to $70^{\circ}$, to avoid superposition of the steps (Hansson, 1991, Yisa, 2002).

Mathematical models can be used in anthropometry to estimate certain measures of the human body in function with other known measures, as statistical correlations between the variables have been significant. In Brazil, these models can be a very important tool in each region due to the existence of a great variety of physical types as a result of the many ethnic groups, in addition to the quite different nutritional and health conditions between the regions (lida, 2005).

The body mass index (BMI) is the anthropometric measure most commonly recommended and widely used for classifying overweight and obesity in adults which is defined as weight in $\mathrm{kg} / \mathrm{height}$ in meters squared (World Health Organization - WHO, 1995; .Rani et al., 1999; Mei et al., 2002).

According to the report of the World Health Organization/Food and Agriculture Organization WHO/FAO (2003), in many regions of the world, especially but not exclusively in the rural areas of developing countries, an appreciable proportion of the population is still engaged in physically demanding activities relating to agricultural practices and domestic tasks performed without mechanization or with rudimentary tools. Also according to this report, body mass index (BMI) can be used to estimate, albeit crudely, the nutritional state and the prevalence of overweight and obesity within a population and the risks associated with it. It does not, however, account for the wide variations in obesity between different individuals and populations.

Though some research gives general information indicating that a body mass index (weight $(\mathrm{kg}) / \mathrm{height}$ $\left(\mathrm{m}^{2}\right)$ ) in the obese range has been associated with an increased risk of injury resulting from motor vehicle crashes, falls and sports activities (Boulanger et al., 1992; Xiang et al., 2005; Pollack et al., 2007), these papers have not been interested in its specific effect on the risks of injury in tractor operators resulting from activities with tractors and agricultural machines.

The study of Virginia agricultural health and safety survey, Mariger et al. (2008) found that the age-adjusted mean BMI of Virginia farmers was 28.5, indicating that they are overweight.

Determining obesity-related differences can provide useful information for understanding the impact of obesity on the performance of occupational activities and the 
subsequent risk of injury, particularly for those tasks requiring static postures or repetitive motions that can be limited by the development of fatigue (Cavuoto and Nussbaum, 2013).

The present work has as its objective the evaluation of the anthropometric model of the agricultural tractor operators in the Toledo - Parana-Brazil region and the nutritional state of these operators.

\section{MATERIALS AND METHODS}

The work was conducted in Toledo Parana-Brazil from September 2003 to June 2004 with 23 workers who were selected from 127 workers and anthropometrically analysed. The tractors analysed in this region, with different models and similar power, represent two thirds of the total tractors sold in the region (ANFAVEA, 2004). The preliminary analysis investigated the characteristic problems of ergonomic concepts based on the large collection of anthropometric information offering support for the development of this research.

The information collection was divided into two sub-systems: The basic information supplied by specialized bibliographies, databases and suppliers of materials and equipment and the analytical compilation produced by experiments and direct observations in the management of agricultural machinery.

To follow criteria similar professional characteristics in order to obtain good representation of the universe of tractor drivers, this research used four sources, geographically distinct, whose operators have knowledge of both types of agricultural tractors analyzed.

The first field sampling was carried out on a farm, which has five MF tractors manufactured between 2003 and 2004, within the established standard for this search. From a population of 18 operators of agricultural machinery farm, a sample of four operators was selected within the established criteria. The second field sampling was performed at another farm, which has five $\mathrm{NH}$ tractors manufactured between 2003 and 2004. In this farm, with a population of nine operators of agricultural machinery, a sample of four operators was also selected obeying the same criteria. The third sample was taken at a meeting of farmers (field day) in the region. At this meeting, in a population of 72 operators analyzed a sample of 12 operators was selected. The fourth data collection was carried out at a dealership for new and used tractors and among 28 operators of agricultural machinery only three met the selection criteria. Thus, to represent the group studied in a total of 127 operators analyzed, 23 agricultural tractor operators were selected obeying criteria anthropometry with a margin of error of $5 \%$ significance.

In the field experiment, the anthropometric evaluation was aimed exclusively at the operators of middle power tractors, similar to the analysed models and with analogous measurements.

Twenty-two measurements of the anthropometric features of 23 tractor operators (Table 1) were selected from two farm tractors. The observations were taken carefully to measure all the dimensions in a correct posture and precise manner. Standing height (stature), body mass, eye height, shoulder height, elbow height, etc. were measured in standing posture for that the subjects were asked to stand on a flat surface; their arms were adjusted according to their height, with their feet closed and their body vertically erected, while their heels, buttocks and shoulders touched the same vertical plane. Similarly, other measurements were recorded in sitting posture, for that the subjects were asked.

An anthropological instrument (anthropometer) was used for taking measurements with an accuracy of $70.25 \mathrm{~mm}$. The data recorded for the subject was mean of four readings. The linear dimensions, taken with the subject standing, were measured directly with an electronic metric system. The dimensions of the seated operators were measured in the seat of the tractor following the procedure used previously with the ISO 7250-1. The anthropometric determination of the operators was conducted following criteria similar to those adopted by lida (2005). The measurements followed a normal distribution, as represented by the average and the standard deviation.

The ISO 7250-1 norm defined anthropometric patterns in 1996. However, this rule is not specific to machine operators and was developed with data on persons of European origin. Operators from foreign countries can differ (Nkakine et al., 2008; Mehta et al., 2008; Kumar et al., 2009), and anthropometric variations can occur within an individual country according to its extent. Thus, an agricultural tractor whose workplace measurements are in accord with international norms will not be comfortable for Brazilian operators.

From the application of the calculation, a 90\% confidence interval (between 5 and 95\%) was determined for the sample of the 23 operators, which differentiates $5 \%$ who are below $1.68 \mathrm{~m}$ in height and $5 \%$ who are above $1.72 \mathrm{~m}$ in height, as well as other dimensions. The principal dimensions (in the projection of the longitudinal vertical plan) measured in the agricultural tractors were the tractor's floor height and foot step height, the least distance of the operator's vision to the ground in front of the tractor and the seat reference point (Figure 1).

The nutritional state was defined based on the WHO's standard for Body Mass Index (BMI) WHO/FAO (2003), considering that a BMI between 18.5 and $24.9 \mathrm{~kg} / \mathrm{m}^{2}$ is in the "normal range"; a BMI between 24.9 and $29.9 \mathrm{~kg} / \mathrm{m}^{2}$ indicates an " Overweight" pre-obese condition; and a BMI above $30.0 \mathrm{~kg} / \mathrm{m}^{2}$ indicates class I "obesity".

\section{RESULTS AND DISCUSSION}

\section{Anthropometric measurements}

The operators' measurements of obtained on the two tractors were compared with the corresponding parameters of the 5th and 95th percentiles to ascertain their appropriateness. In Table 1, the anthropometric data obtained from the body's members that are associated with the act of getting on and off the tractor are presented. The corresponding dimensions are shown in Figure 2.

The results show that taller operators can be at a reasonable advantage for the visibility at various stages, during tasks performed over a long period such as ploughing and sowing (up to $12 \mathrm{~h}$ per day) (Table 1 ). The regression analysis shows a positive linear statistically significant relationship $(p<0.01)$ between the operator's height and the dimensions of their members (Figure 3). The statistical analysis revealed a correlation of 0.9057 between the variables of body height and knee height and of 0.8547 between the variables of body height and full hand length. At a height of $60 \mathrm{~cm}$ of access to the tractor, the operators around the margin of the 5th percentile can exert more effort than those around the 95th percentile. Although there is no recommended value available for the ideal step access height, the general opinion of all of the operators is that higher steps cause more discomfort.

Though the overall evaluations were homogeneous, 
Table 1. Measurements of the anthropometric characteristics of 23 tractor operators in Toledo - PR in the static body.

\begin{tabular}{|c|c|c|c|c|c|c|}
\hline \multicolumn{2}{|c|}{ Operators } & \multirow{2}{*}{$\begin{array}{c}\begin{array}{c}\text { Standard } \\
\text { deviation }\end{array} \\
12.1\end{array}$} & \multirow{2}{*}{$\begin{array}{c}\begin{array}{c}\text { Percentile } \\
\mathbf{5}^{\text {th }}\end{array} \\
22.5\end{array}$} & \multirow{2}{*}{$\begin{array}{c}\text { Mean } \\
42.5\end{array}$} & \multirow{2}{*}{$\begin{array}{c}\begin{array}{c}\text { Percentile } \\
\mathbf{9 5}^{\text {th }}\end{array} \\
62.5\end{array}$} & \multirow{2}{*}{$\begin{array}{c}\text { Difference } \\
\text { between } 5^{\text {th }} \text { and } \\
95^{\text {th }} \text { percentiles }\end{array}$} \\
\hline a.1 & Age (years) & & & & & \\
\hline \multirow[t]{2}{*}{ a.2 } & Body mass (kg) & 10.3 & 62.8 & 79.7 & 96.7 & \\
\hline & Measurements taken with sub & & & & & \\
\hline b.1 & Height (erect) & 51.0 & $1,649.0$ & $1,733.0$ & $1,817.0$ & 168.0 \\
\hline b.2 & Eye height & 51.6 & $1,533.0$ & $1,618.0$ & $1,703.0$ & 170.0 \\
\hline b.3 & Shoulder height & 44.6 & $1,354.0$ & $1,427.0$ & $1,500.0$ & 146.0 \\
\hline b.4 & Elbow height & 26.3 & $1,012.0$ & $1,056.0$ & $1,099.0$ & 87.0 \\
\hline b.5 & Functional lower arm height & 35.1 & 682.0 & 740.0 & 797.0 & 115.0 \\
\hline b. 6 & Functional upper arm height & 69.2 & $1,935.0$ & $2,049.0$ & $2,162.0$ & 227.0 \\
\hline \multirow[t]{2}{*}{ b.7 } & Full-hand length & 18.4 & 702.0 & 733.0 & 763.0 & 61.0 \\
\hline & Measurements taken with sub & & & & & \\
\hline c.1 & Popliteal height & 6.7 & 447.0 & 458.0 & 469.0 & 22.0 \\
\hline c. 2 & Height (from the floor) & 26.7 & $1,259.0$ & $1,303.0$ & $1,347.0$ & 88.0 \\
\hline c. 3 & Eye height (from the floor) & 30.7 & $1,162.0$ & $1,212.0$ & $1,263.0$ & 101.0 \\
\hline c. 4 & Shoulder height (from the floor) & 27.4 & 969.0 & $1,014.0$ & $1,059.0$ & 90.0 \\
\hline c.5 & Elbow height (from the floor) & 24.1 & 610.0 & 650.0 & 690.0 & 80.0 \\
\hline c. 6 & Knee height & 16.2 & 516.0 & 543.0 & 570.0 & 54.0 \\
\hline c.7 & Thigh length & 31.0 & 458.0 & 509.0 & 560.0 & 102.0 \\
\hline c. 8 & Forearm & 12.8 & 338.0 & 359.0 & 380.0 & 42.0 \\
\hline c. .9 & Buttock-knee length & 21.2 & 555.0 & 590.0 & 624.0 & 69.0 \\
\hline c. 10 & Elbow-to-elbow width & 14.7 & 495.0 & 519.0 & 543.0 & 48.0 \\
\hline \multirow[t]{2}{*}{ c.11 } & Seat breadth & 18.2 & 343.0 & 373.0 & 403.0 & 60.0 \\
\hline & Hand $(\mathrm{mm})$ & & & & & \\
\hline d.1 & Functional length & 5.0 & 99.0 & 107.0 & 115.0 & 16.0 \\
\hline d.2 & pan width & 5.9 & 202.0 & 212.0 & 222.0 & 20.0 \\
\hline d.3 & Functional grip & 1.8 & 27.0 & 30.0 & 33.0 & 6.0 \\
\hline
\end{tabular}

The basic anthropometrics measurements were defined by Wilkinson (1991).

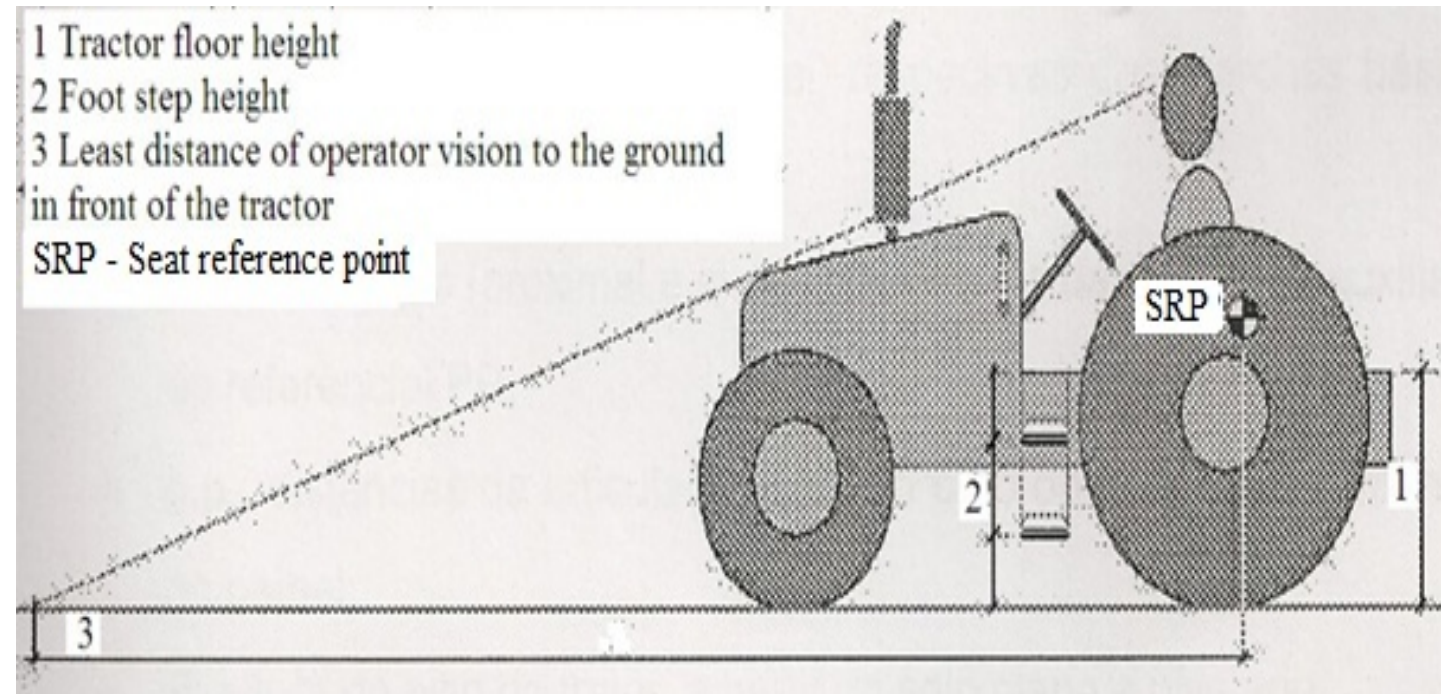

Figure 1. Measurements of selected tractor dimensions. 


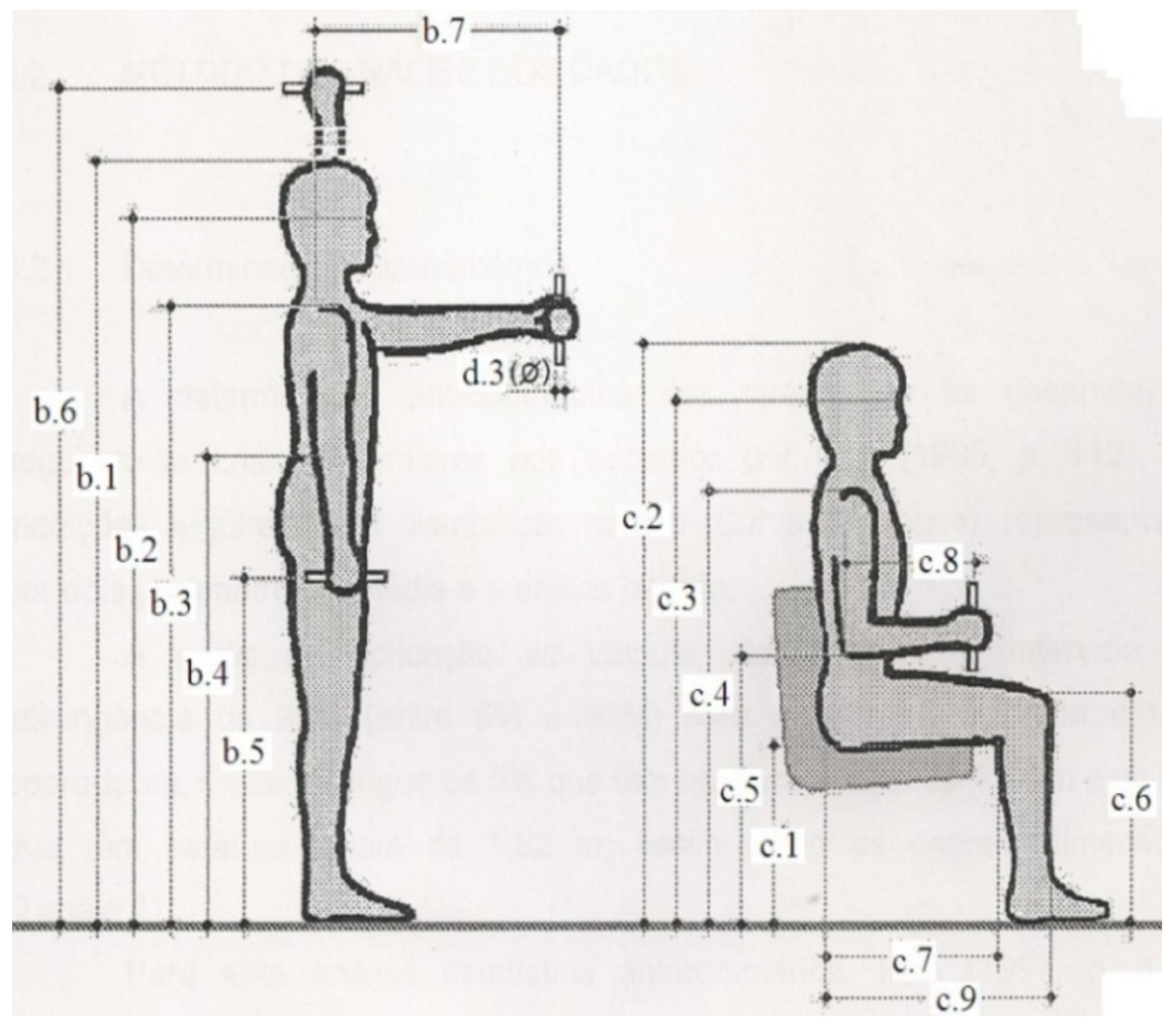

Figure 2. Anthropometric data of tractor operators (Wilkinson, 1991).

considerable variations in stature were observed, from 1,649 to $1,817 \mathrm{~mm}$ in height. Body weight also presented significant variations, from 61.8 to $96.7 \mathrm{~kg}$.

In accordance with lida (2005), these results allow the development of a mathematical model for the variables of the full hand length and the forearm in the function of the knee height. They are presented in Figure 3 and show the dependent proportionality between these measures. It is also observed that the dimensions of the members are proportional to the knee height of the operators. We performed a Pearson's correlation analysis to identify the dependence of the anthropometric variables of full hand I ength and forearm on knee height. It provided evidence of a strong positive correlation between these variables ( 0.78 and 0.77 , respectively). The seat-man-pedal assembly can be represented by a kinematic chain of linkages at a horizontal distance in front of the seat reference point (SRP), a vertical distance above and below the SRP and direction of thrust and the use of the steering wheel for bracing (Pheasant and Harris, 1982). The variables investigated in the models can be very useful in making decisions about the design of the tractor's workspace to improve both efficiency and operator comfort.
The specific dimensions of the tractors evaluated are presented in Table 2 and elucidated in Figure 4. The results show that the steering wheel of the $\mathrm{NH}$ tractor at the full back adjustment has a distance from the seat reference point (SRP) of 695 and of $760 \mathrm{~mm}$ in the MF tractor. The subjects with the 95th percentile full hand reach $(763 \mathrm{~mm})$ have a comfortable reach, whereas subjects with the 5 th percentile full hand reach $(702 \mathrm{~mm})$ do not have a similar comfortable hand reach with the MF tractor. The same dynamic can be observed when we compare the seat height of the tractors (Table 2, h) with the popliteal height of the operators (Table 1, c1). The linear regression models, in Figure 3 , show that the height of all of the subjects analysed is sufficient for working comfortably while operating the $\mathrm{NH}$ tractor. For this way, the steering wheel can be adjusted to the operator's height. The safety features in the design of the operator's seat are of prime importance in reducing the static work of the muscles. The ability to adjust the seat and controls is necessary to accommodate operators of different statures and physiques comfortably (Yadav and Tewari, 1998).

In accordance with Schlosser et al. (2000), the knee height is used to define the seat height in regard to the 

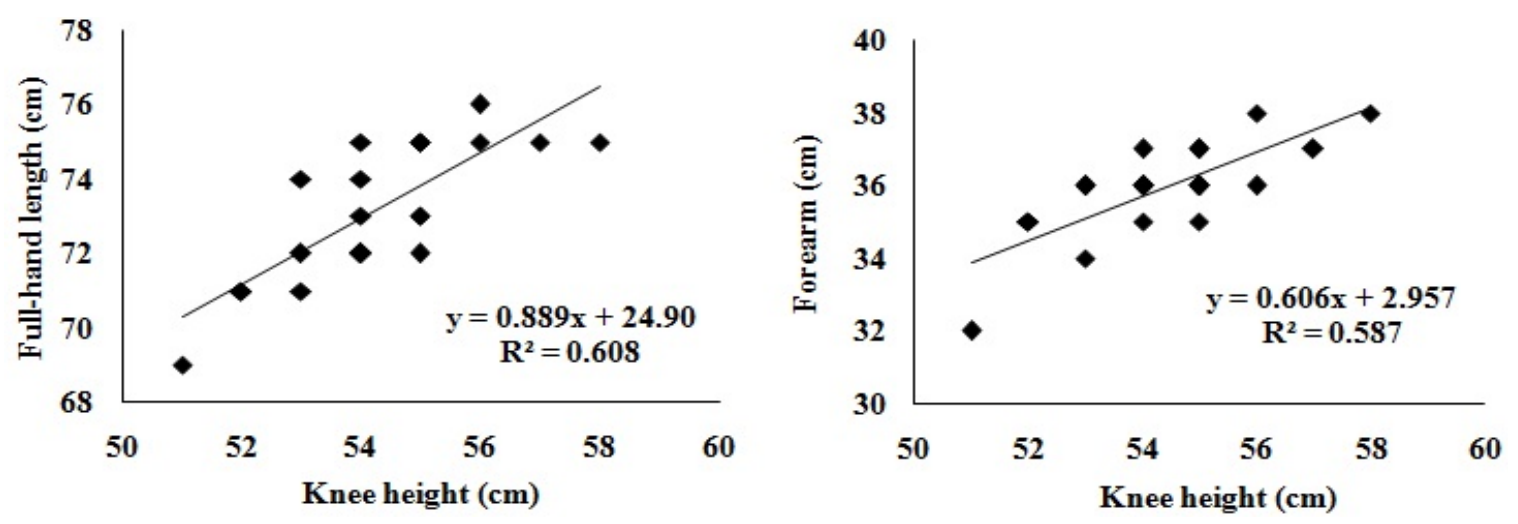

Figure 3. Dimensions of full hand length and forearm as in function of the knee height.

Table 2. Dimensions and characteristics evaluated for two tractors.

\begin{tabular}{lcc}
\hline Tractors & NH & MF \\
\hline Model & 7630 & 292 \\
External dimensions & 4,115 & 4,250 \\
Mass $(\mathrm{kg})$ & 3,039 & 3,575 \\
Power $(\mathrm{kW}) \mathrm{rpm}$ & $(75.8) 2100$ & $(77.2) 2200$ \\
D $(\mathrm{mm})$ & $545-695$ & $610-760$ \\
d $(\mathrm{mm})$ & 150 & 150 \\
$\mathrm{~h}(\mathrm{~mm})$ & 460 & 470 \\
b (mm) & 360 & 390 \\
a (mm) & $40^{\circ}$ & $40^{\circ}$ \\
e (mm) & 26 & 26 \\
$\phi(\mathrm{mm})$ & 390 & 390 \\
x (mm) & 720 & 730 \\
mPR $(\mathrm{mm})$ & $540-630$ & $620-720$ \\
MPR $(\mathrm{mm})$ & $470-620$ & $610-700$ \\
Tractor floor height & 1090 & 920 \\
Steps $(\mathrm{mm})$ & & \\
$1^{\circ}$ step & 600 & 590 \\
$2^{\circ}$ step & 260 & 330 \\
$3^{\circ}$ step & 230 & There is not \\
Floor & 1,090 & 920 \\
\hline
\end{tabular}

operating platform. This height must be such that the operator's feet are always supported and that the operator has easy access to the foot controls. In this scenario, it is possible to infer that the vertical position of the seat, defined by international standards (ISO 7250-1, Schlosser et al., 2000), is in accord with the standards of the operators of the Toledo region (Figure 3). In all of the analysed cases, the operators had to alter their seated positions to use the gearshift, hydraulic controls and many other controls, still that eventually. It was observed that the distance of the operator to the front panel and to the gearshift provokes flexion of the spinal column in some of the operators (Table 2).
Table 2 presents the dimensions of the intervals between the access steps in the evaluated tractors. The initial interval is measured between the ground and the first step, successively, up to the tractor's floor. The access steps checked are vertical. The analysed tractors' access steps do not meet ergonomic standards (Hansson, 1991) regarding their measurements and their angles of inclination. For Hansson (1991), the process of getting on and off machinery that must be mounted or dismounted frequently should be convenient and risk-free. The machine must be designed so that mounting and dismounting are safe and convenient, without the need for uncomfortable body movements. The steps should be 


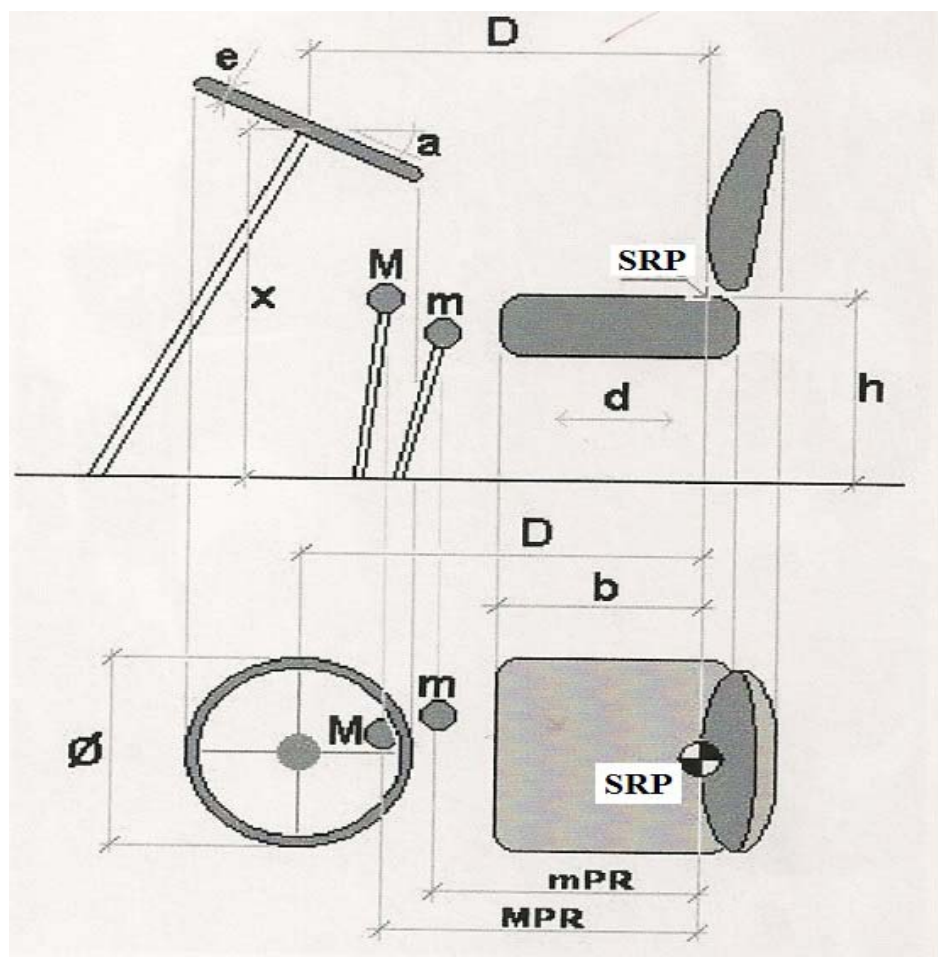

Figure 4. Dimensions and locations of controls and workspace: (a) horizontally inclined steering wheel (b) seat pan depth, (d) seat reach adjustment, (D) distance of steering wheel from seat reference point (PR), (e) steering wheel thickness, (h) seat height, $(x)$ steering wheel centre height, $(\phi)$ steering wheel diameter, (mPR) distance between the speed reduction lever and the seat reference point, (MPR) distance between the speed lever and the seat reference point (Table 2).

designed or positioned so that they are unlikely to be damaged during work.

The steps have different spacing, with variations of 230 to $600 \mathrm{~mm}$. There are reports of frequent accidents due to falls. It was observed that the height of the access steps exceed the ergonomic limits, which are from 200 to $300 \mathrm{~mm}$ (Hansson, 1991), with equal heights and a minimum width of $100 \mathrm{~mm}$. The minimum horizontal reach should be $150 \mathrm{~mm}$ with an inclination of $65^{\circ}$ to $70^{\circ}$, avoiding the superposition of the steps.

Five anthropometric measures were compared with the results obtained in other literature (Table 3 ).

The results show that there was no difference between the general types of the operators of the South region of Brazil (Rio Grande do Sul and Botucatu - SP) obtained, respectively, in the work of Schlosser et al. (2000) and those of Rossi and Santos (2009) for the measures of height when standing. Our results show also that the Toledo operators are taller than the English operators described by Dul and Weerdmeester (1995). When we compare only the operators of the southern region of Brazil, we observe that for the measures of sitting eye height and arm reach, these dimensions were less for the Toledo region operators; however, on examination, the
Toledo operators had longer thigh lengths than those that were studied by Schlosser et al. (2000), Rossi and Santos (2009) and Dul and Weerdmeester (1995). This characteristic of our regions tractor operators allows them to be more comfortable because longer thighs gives them better access to the clutch pedals, the brakes and the accelerator, quicker with less effort. This enables the operator to maintain his normal position. The results of the sitting knee height were similar.

\section{Body mass index}

The body mass index (BMI) in relation to the age of the tractor operators is shown in Figure 5. The relationship between the body mass and the square of the height allowed the Body Mass Index to be valued in relation to the obesity classification of the tractor operators classified according to the WHO/FAO (2003) criteria.

It was confirmed that the operators' body mass varies from normal to obese. Approximately $35 \%$ of the operators in this sample were in the normal range, with a BMI between 18.5 and $24.9 \mathrm{~kg} / \mathrm{m}^{2}, 48 \%$ were overweight (pre-obese, with an index between 25 and $29.9 \mathrm{~kg} / \mathrm{m}^{2}$ ) 
Table 3. Comparison of the anthropometric standards of the agricultural tractor operators of the Toledo region Paraná.

\begin{tabular}{lcccc}
\hline Body measurements $(\mathbf{m m})$ & Toledo - PR & Botucatu - SP & England - UK & Rio Grande do Sul \\
\hline Standing height & 1,733 & 1,721 & 1,675 & 1,739 \\
Eye height from the seat & 752 & 782 & 765 & 820 \\
Sitting knee height & 543 & 535 & n.d & 552 \\
Arm reach & 733 & 793 & n.d & 896 \\
Thigh length & 509 & 482 & 488 & 458 \\
\hline
\end{tabular}

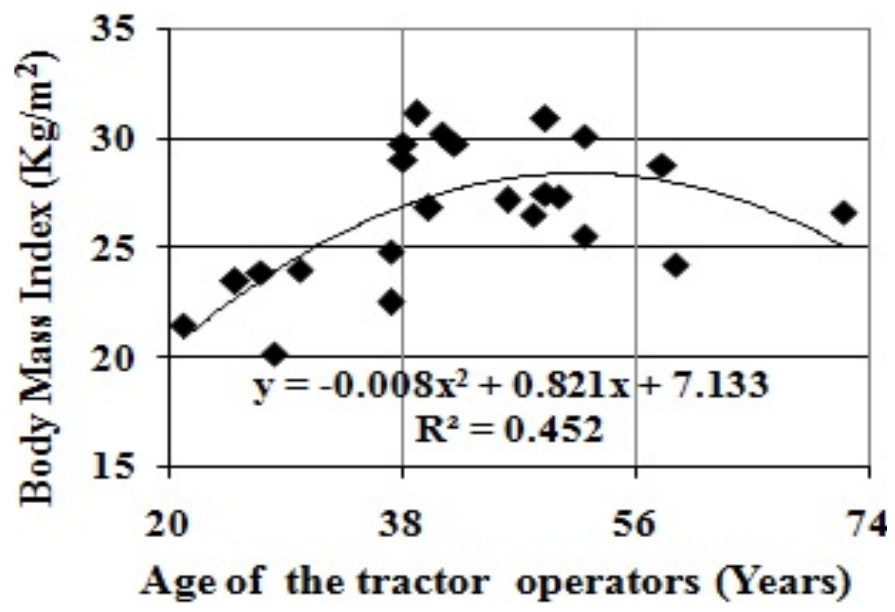

Figure 5. Obesity index of the agricultural tractor operators.
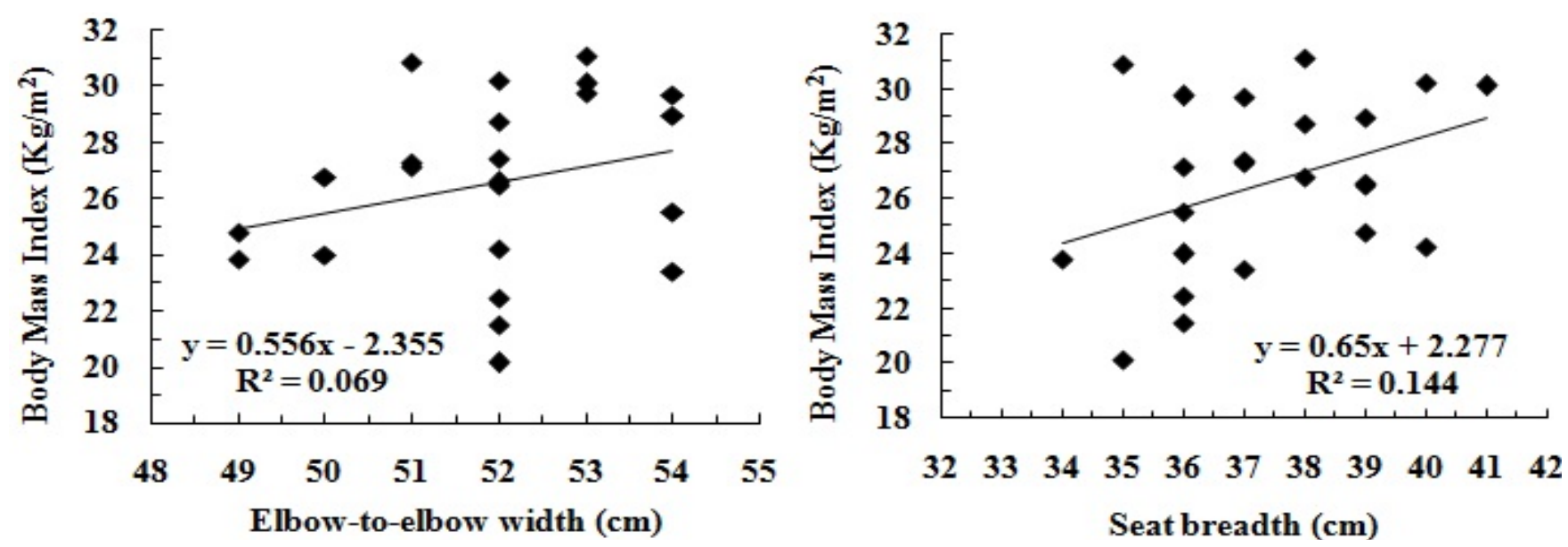

Figure 6. Relationships between the body mass index and elbow-to-elbow width and seat breadth fit with regression linear curves.

and $17 \%$ qualified as obese (30.1 to $30.9 \mathrm{~kg} / \mathrm{m}^{2}$ ) (WHO/FAO (2003)).

It was observed also that of the operators with BMI characteristics in the normal range, approximately $30 \%$ were less than 38 years old, and those with characteristics of pre-obesity and obesity were more than
38 years old.

Linear regression curves of the Body Mass Index (BMI) in relation to elbow-to-elbow width and seat breadth variables were developed (Figure 6). The data showed moderate positive correlations between the BMI and these variables, 0.3 to elbow-to-elbow width and 0.4 to 
seat breadth, respectively.

Current evidence shows obesity-related differences in the elbows' extension and in the quadriceps (Maffiuletti et al., 2007).

BMI can be used to estimate, albeit crudely, the prevalence of overweight and obesity within a population and the risks associated with it. It does not, however, account for the wide variations in obesity among different individuals and populations.

In recent years, different ranges of BMI cut-off points for overweight and obesity have been proposed, in particular for the Asia-Pacific region (WHO, 2000). Nevertheless, the consensus was that the median BMI for the adult population should be in the range of 21 to 23 $\mathrm{kg} / \mathrm{m}^{2}$ to achieve optimum health, and the goal for individuals should be to maintain a $\mathrm{BMI}$ in the range of 18.5 to $24.9 \mathrm{~kg} / \mathrm{m}^{2}$ (WHO/FAO, 2003).

\section{Conclusion}

The median stature of the operators inside the analysed parameters is similar to that quoted in the literature of Brazil's southern region and within the confidence intervals of anthropometric evaluations. The vertical position of the seat, defined by international standards, is in accordance with the standard Toledo region operators. The heights between the access steps are varied and unsuitable, as is the inclination of the staircase. The results show that there was no difference between the general types of the operators of Brazil's South region regarding the measure of standing height. Of the operators who presented BMls with characteristics in the normal weight range, seven were less than 38 years old, and those with characteristics of pre-obesity and obesity were more than 38 years old.

\section{Conflict of Interest}

The authors have not declared any conflict of interest.

\section{REFERENCES}

ANFAVEA - Associação Nacional de Fabricantes de Veículos Automotores. (2004) http://www.anfavea.com.br. Accessed July 2, 2004.

Boulanger BR, Milzman D, Mitchell K (1992). Body habitus as a predictor of injury pattern after blunt trauma. J. Trauma 33:228-232. http://dx.doi.org/10.1097/00005373-199208000-00011PMid:1507286

Cavuoto LA, Nussbaum MA (2013). Obesity-related differences in muscular capacity during sustained isometric exertions. Appl. Ergon. 44:254-260.

http://dx.doi.org/10.1016/j.apergo.2012.07.011PMid:22858008

Dul J, Weerdmeester B (1995). Ergonomia prática. Ed, Edgard Blucher, P.143.PMid:8592943

Hansson J (1991). Ergonomic checklist for agricultural machinery and similar equipment. Saint Joseph-Michigan: ASAE 2950 Niles Rd. Human Factors, module P. 2.

lida I (2005). Ergonomia. projeto e produção. São Paulo: Edgard Blücher P. 614.
INCRA-Instituto Nacional de Colonização e Reforma Agrária (2008). http://www.incra.gov.br/_html/serveinf.html 11 Accessed in March 11, 2008

ISO 7250 -1 (2008). Basic human body measurements for technological design. Part 1: Body measurement definitions and landmarks. P. 10.

Kumar A, Bhaskar G, Singh JK (2009). Assessment of controls layout of Indian tractors. Appl. Ergon. 40:91-102. http://dx.doi.org/10.1016/j.apergo.2008.01.017 PMid:18339354

Maffiuletti N, Jubeau M, Munzinger $U$, Bizzini M, Agosti F, Col A, Lafortuna C, Sartorio, A (2007). Differences in quadriceps muscle strength and fatigue between lean and obese subjects. Eur. J. Appl. Physiol. 101:51-59.

http://dx.doi.org/10.1007/s00421-007-0471-2 PMid:17476522

Mariger SC, Grisso RD, Perumpral JV, Sorenson AW, Christensen NK, Miller RL (2008). Virginia Agricultural Health and Safety Survey. J. Agric. Safety Health 15(1):37-47. http://dx.doi.org/10.13031/2013.25414

Mehta CR, Gite LP, Pharade SC, Majumder J, Pandey MM (2008). Review of anthropometric considerations for tractor seat design. Int. J. Indust. Ergon. 38:546-554.

http://dx.doi.org/10.1016/j.ergon.2007.08.019

Mei Z, Grummer-Strawn LM, Pietrobelli A, Goulding A, Goran MI, Dietz WH (2002). Validity of body mass index compared with other bodycomposition screening indexes for the assessment of body fatness in children and adolescents. Am J Clin Nutr 75:978-85.PMid:12036802

Nkakine SO, Akor AJ, Ayotamuno JM (2008). Ergonomics of tractor operation control for comfort in Nigeria. J. Agric. Eng. Technol. JAET. 16(1):4-11.

Pheasant ST, Harris CM (1982). Human strength in the operation of tractor pedals. Ergonomics 25(1):53-63. http://dx.doi.org/10.1080/00140138208924926 PMid:7128559

Pollack KM, Sorock GS, Slade MD, Cantley LC, Sircar K, Taiwo O, Cullen MR (2007). Association between Body Mass Index and Acute Traumatic Workplace Injury in Hourly Manufacturing Employees. Am. J. Epidemiol. 166:204-211. http://dx.doi.org/10.1093/aje/kwm058 PMid: 17485732

Rani CSS, Rema M, Deepa R, Premalatha G, Ravikumar R, Mohan A, Sastry NG, Ramu M, Saroja R, Kayalvizhi G, Mohan V (1999). THE Chennai urban population study (cups) - Methodological details (Cups paper $n^{\circ}$. 1). Int. J. Diab. Dev. Count. 19:149-155.

Rossi MA, Santos JEG (2009). Análise comparativa de medidas corporais em operadores de máquinas agrícolas. Revista Energia na Agricultura. 24(4):77-91.

Schlosser JF, Debiasi H, Parcianello G, Rambo L (2000). Anthropometric studies applied to the millennium. 2: 226-227.

Tewari VK, Bhoi PK, Dhav R (2002). Healthy and comfortable environment to the tractor operator during farm work. ASAE Annual international meeting / CIGR 15th World Congress, Hyatt Regency Chicago Illinois, U. S. A., July $28-31$, P. 2.

Victor MR, Nath S, Verma A (2002). Anthropometric survey of Indian farm workers to approach ergonomics agricultural machinery design. Appl. Ergon. 33:579-581. http://dx.doi.org/10.1016/S00036870(02)00044-3

World Health Organization - WHO (1995). Physical status: The use and interpretation of anthropometry. Report of a WHO Expert Committee. World Health Organ. Tech. Rep. Ser. 854:1-452.PMid:8594834

World Health Organization - WHO (2000) Regional Office for the Western Pacific/International Association for the Study of Obesity/International Obesity Task Force. The Asia-Pacific perspective: redefining obesity and its treatment. Sydney, Health Communications Australia,

World Health Organization / Food and Agriculture Organization WHO/FAO (2003). Expert Consultation on Diet, Nutrition and the prevention of Chronic Diseases. Geneva, Switzerland, http://whqlibdoc.who.int/trs/who_trs_916.pdf. Accessed in August 17, 2012

Wilkinson RH (1991). Anthropometrics and workplace design. Saint Joseph-Michigan: ASAE 2950 Niles Rd. Human Factors, module P. 7.

Xiang H, Smith GA, Wilkins JR (2005). Obesity and risk of nonfatal unintentional injuries. Am. J. Prev. Med. 29:41-5. http://dx.doi.org/10.1016/j.amepre.2005.03.013 PMid:15958250 
Yadav R, Tewari VK (1998). Tractor operator workplace design - A review. J. Terramechan. 35(1):41-53.

http://dx.doi.org/10.1016/S0022-4898(98)00011-1

Yadav R, Tewari VK, Prasad N (1999). An anthropometric model of Indian tractor operators. Agricultural Mechanization in Asia, Africa and Latin America, Tokio, 30(1):25-28.
Yisa MG (2002). Ergonomics of tractors assembled in Nigeria. Biosystems Engineering, Minna, Niger, State 81(2):169-177. http://dx.doi.org/10.1006/bioe.2001.0050 